\title{
Immuno-Metabolic Modulation of Liver Oncogenesis by the Tryptophan Metabolism
}

\author{
Véronique Trézéguet $\mathbb{1}$, Hala Fatrouni and Aksam J. Merched * \\ MiRCade Team, BMGIC, INSERM U1035, University of Bordeaux, F-33000 Bordeaux, France; \\ veronique.trezeguet-busquet@u-bordeaux.fr (V.T.); hala.fatrouni@u-bordeaux.fr (H.F.) \\ * Correspondence: aksam.merched@u-bordeaux.fr; Tel.: +33-5-47-47-16-87
}

Citation: Trézéguet, V.; Fatrouni, H.; Merched, A.J. Immuno-Metabolic Modulation of Liver Oncogenesis by the Tryptophan Metabolism. Cells 2021, 10, 3469. https://doi.org/ 10.3390/cells10123469

Academic Editor: Alessandro Pogg

Received: 4 November 2021

Accepted: 1 December 2021

Published: 9 December 2021

Publisher's Note: MDPI stays neutral with regard to jurisdictional claims in published maps and institutional affiliations.

Copyright: (c) 2021 by the authors. Licensee MDPI, Basel, Switzerland. This article is an open access article distributed under the terms and conditions of the Creative Commons Attribution (CC BY) license (https:// creativecommons.org/licenses/by/ $4.0 /)$.

\begin{abstract}
Metabolic rewiring in tumor cells is a major hallmark of oncogenesis. Some of the oncometabolites drive suppressive and tolerogenic signals from the immune system, which becomes complicit to the advent and the survival of neoplasia. Tryptophan (TRP) catabolism through the kynurenine $(\mathrm{KYN})$ pathway was reported to play immunosuppressive actions across many types of cancer. Extensive debate of whether the culprit of immunosuppression was the depletion of TRP or rather KYN accumulation in the tumor microenvironment has been ongoing for years. Results from clinical trials assessing the benefit of inhibiting key limiting enzymes of this pathway such as indoleamine 2,3-dioxygenase (IDO1) or tryptophan 2,3-dioxygenase (TDO2) failed to meet the expectations. Bearing in mind the complexity of the tumoral terrain and the existence of different cancers with IDO1/TDO2 expressing and non-expressing tumoral cells, here we present a comprehensive analysis of the TRP global metabolic hub and the driving potential of the process of oncogenesis with the main focus on liver cancers.
\end{abstract}

Keywords: tryptophan; kynurenin; metabolism; TDO2; IDO1; liver cancer; hepatoblastoma; immuno-oncology

\section{Introduction to Liver Cancers}

\subsection{The Liver, an Extraordinary Organ with Multiple Functions}

The liver is an essential organ involved not only in digestion but also in many other functions, among them immunotolerance [1]. Indeed, it is continuously exposed to antigens from food intake, gut microbiome, and possibly from pathogens. Kupffer cells, dendritic cells, and lymphocytes $\mathrm{T}$ participate in this tolerance.

Any dysfunction of the liver can therefore lead to important metabolic or immunological disorders, eventually threatening the survival of the organism and/or leading to liver tumorigenesis. In 2020, liver cancer ranked 6th in the world in terms of incidence (around 906,000 new cases) and 3rd in terms of mortality (around 830,000 deaths), with disparities between men and women as incidence and mortality rates were 2-3 times higher in men [2]. Liver cancer is expected to increase by $50 \%$ in the next 20 years with major geographical disparities in prevalence worldwide [3].

\subsection{Hepatocellular Carcinoma in Adults}

Hepatocellular carcinoma (HCC), also called hepatocarcinoma, is an adult primary liver cancer that develops from hepatocytes in 75-85\% of cases [4] and, most of the time, in a diseased (chronic liver inflammation, fibrosis) and/or cirrhotic organ [5]. Other rarer forms of primary liver cancer can develop from cells in the bile ducts (cholangiocarcinoma, 10-15\% of cases [4]) or, much more rarely, from blood vessels (epithelioid hemangioendothelioma). All causes of chronic liver disease are therefore directly or indirectly responsible for HCC. Among them the most frequent are the hepatitis $\mathrm{B}$ and $\mathrm{C}$ viruses, representing $56 \%$ and $20 \%$ of liver cancer deaths worldwide in 2012, respectively [6], alcohol abuse, aflatoxin B 
exposure, smoking, and non-alcoholic steatohepatitis (NASH). Diabetes and obesity are also risk factors of HCC. Hepatocarcinoma's incidence has been steadily increasing for several years, due to the increase in viral infections or environmental toxins $[7,8]$. The etiology of HCC also lies in alterations of TERT (telomere reverse transcriptase), oncogenes and tumor suppressor genes (P53, etc.), and genes that lead to aberrant cell signaling pathways (Wnt- $\beta$-catenin pathway, etc.), in parallel with the development of cirrhosis and liver fibrosis [9].

In most cases, symptoms are absent in the early stages of the disease. By the time symptoms such as jaundice and weight loss occur, it is usually too late and the available treatment options extend survival by only a few weeks or months. This is why regular surveillance is recommended for patients with cirrhosis or chronic Hepatitis B or C Virus infections. Usually, it consists in an ultrasound scan, which may be combined with an evaluation of serum markers such as Apha-fetoprotein (AFP) or Glypican 3 (GPC3).

Staging is a requisite for proposing the best treatment strategy, and it must consider the underlying liver condition that will affect the evolution of the disease and dictate the applicability and effectiveness of the treatment. Around 18 staging classifications have been proposed, and are reviewed in [10]. The number and size of nodules and the presence of an underlying liver disease are the most common criteria but the presence of tumor and vascular invasions or the extent of liver involvement is also examined. Some of these staging systems are also of prognostic value. However, it appears that there is no real consensus when it comes to deciding which staging system offers the best classification. Though the main drivers of HCC are numerous, the molecular characterization was thus far of no help for stratification.

Surgical resection and liver transplantation are the best curative options, as they improve the survival chances, at least at an early stage of HCC. Only a quarter of the liver mass is necessary for a human organism to live normally. After resection, the liver has extraordinary regenerative capacities as new cells are rapidly generated to allow the remaining liver to grow back to its original size. Transcatheter arterial chemoembolization (TACE) or radioembolization (TARE) leading to tumor necrosis are proposed for intermediate stage patients. For the most advanced cases, multikinase inhibitors sorafenib or regorafenib can extend life by a few months [11,12]. Recently, FDA approved as second line-therapy for advanced HCC immune check-point inhibitors, alone or in combination $[13,14]$, and anti-VEGF antibodies as reviewed in [14]. Attempts have been made to vaccinate with HCC specific antigens such as AFP, GPC3, or the multidrug resistance-associated protein MRP3. They were not associated with an increased overall survival [1]. The complexity of the role of the liver in self-defense and immunotolerance makes it difficult to envision immunotherapy treatment and underlines the urgent need for better understanding the immune environment in HCC to provide efficient treatments for longer survival and better quality of life.

Any treatment that may improve liver conditions, such as steatosis, fibrosis, NASH, could help reduce HCC risk. In this context, statins have been evaluated, as reviewed in $[13,15]$. Statins inhibit the rate-limiting step of cholesterol synthesis catalyzed by the 3-hydroxy-3-methylglutaryl CoA reductase (HMG-CoA reductase). Since their discovery in 1973, they are widely used as lipid lowering agents in the prevention of heart attack and stroke. They are now considered potentially chemopreventive thanks to several observational and experimental studies, although additional investigations are needed to meet these expectations. [13,15].

\subsection{Hepatoblastoma in Children}

Hepatoblastoma (HB) is a rare primary liver tumor with a worldwide incidence of 1.5 cases/million children per year. HB usually affects children under 5 years of age [16] for whom it is the most common liver tumor with the majority of cases appearing before 18 months. HB derives from parenchymal liver cells or hepatoblasts. It can occur sporadically, in children prematurely born or with a low birth weight, or in children with a 
family history of genetic diseases such as adenomatous polyposis or Beckwith-Wiedemann syndrome. Children who had hepatitis B at an early age or biliary atresia are at greater risk of developing the disease. HB can metastasize, mostly in the lung and the abdomen.

The mainstay of curative therapy based on clinical parameters and risk assessment [17] is a complete surgical resection. When not possible at first line, cisplatin and doxorubicinbased chemotherapies can help reduce the size of the tumor before resection. Four international groups have established standards of risk and treatment strategies that have helped to achieve a five-year survival rate of nearly $80 \%$, up from $27 \%$ in the early 1990 s [18], but the prognosis remains poor in $20 \%$ of cases. Hence, the side effects of chemotherapy and the management of the refractory cases remain to be improved.

Cisplatin is known to induce cytotoxicity, neurotoxicity, and nephrotoxicity, and cardiotoxicity of doxorubicin limits its use to treat HB. Other platinum derivatives such as carboplatin and oxaliplatin induced less cytotoxicity but were also less effective than cisplatin in HB treatment. These drugs induce irreversible DNA damage leading to cell death. The mechanisms of HB resistance to platinum derivatives could arise from DNAunrelated effects of platinum and still need to be clarified [19]. Improvements in the understanding of $\mathrm{HB}$ are therefore of utmost importance. This implies answering several fundamental questions, including that of the HB driver genes and the evaluation of their drug-generability.

$\mathrm{HB}$ is associated with a significant increase in serum alpha-fetoprotein, the level of which is used as a prognostic and diagnostic marker [20]. $\beta$-catenin and the Wnt pathway were identified as key drivers of sporadic HB pathogenesis [21]. The Wnt/ $\beta$ catenin has a key role in the development, regeneration, and zonation of the liver [22]. However, the list is far from close as cancers emerge as complex pathologies with different outcomes even though deriving from the same organ. For instance, in 2008, a 16-gene signature was proposed to discriminate two distinct HB subgroups [23], C1 and C2, and was further adopted.

More recently, a transcriptomic study was performed on tumor and non-tumor tissues from 22 hepatoblastoma patients. A 4-gene molecular signature was thus proposed to classify $\mathrm{HB}$ in three different types, C1, C2A, and C2B [24] based on the previous classification and not overlapping with the 16-gene signature. The $\mathrm{C} 1$ patients are at low risk. In the $\mathrm{C} 2$ types, which are of poorer prognosis, the C2A group is associated with high proliferation while the C2B type exhibits epithelial-mesenchymal transition features. Though different classifications are now internationally recognized, they are questioned because of the low number of patient samples and seem difficult to be validated in larger cohorts of patients. This stresses more than ever the need for a deeper understanding of the molecular biology of HB to propose other therapeutic options with less toxicity, notably for the chemoresistant HB. Research interests should focus on the crosstalk between two emerging hallmarks of cancer, metabolism and inflammation [25], whose better understanding may unravel new leads for such therapeutic perspectives.

\section{Importance of Metabolism as a Feature for Cancer}

Nutritional status is known to regulate cell signaling since the discovery in the 1970s that glucose levels were modifying hepatic ATP levels and leading to various consequences on organite structures and protein modifications such as phosphorylation [26]. For example, glutamine is one of the most consumed amino acids by mammalian cells and its shortage is compensated for by activating EGFR/Pak signaling in pancreatic cancer cells [27].

Metabolites, issued from nutrient consumption, are increasingly considered not only as end products or substrates of enzymatic reactions but also as signaling molecules that eventually govern and modulate many cellular processes among which protein function, cell signaling, gene expression, and intercellular communication [28]. Hence, lipids are not only components of cell membranes or used as energy storage, but have been shown to regulate signaling pathways such as those of PPAR $\beta / \partial$, EGFR-KRAS, or NF-kB [29]. AMPK and mTORC1 signaling were also described as "master regulators" of cellular 
metabolism [29] and sensing of the status of both glucose and energy by AMPK and mediation of amino acid sensing by mTOR signaling are well documented nowadays [28].

Nutrient/metabolite sensing and signaling in cancer cells is an emerging field since the discovery of the oncometabolite 2-hydroxyglutarate (2HG). Mutations of the isocitrate dehydrogenases 1 and 2 (IDH1/2) were discovered as cancer drivers and it was observed that they occur in the catalytic site of IDH1/2, conferring to the mutant enzymes the ability to synthesize $2 \mathrm{HG}$, responsible for triggering malignant transformation and leading to the development of some cancers [30]. More specific but global metabolic alterations in liver cancers are related to the modulation of the Warburg shift (from mitochondrial oxidative phosphorylation toward glycolysis and lactate production) and the upregulation of lipid catabolism. In depth analysis of all the changes in these catabolic pathways of lipid metabolism, e.g., lipogenesis and fatty acid oxidation, and the role of acetyl-CoA at the center of many metabolic pathways are reviewed elsewhere [15]. Metabolites from other nutrients such as L-tryptophan (TRP) are getting more attention for their contribution in oncogenic and immunomodulatory mechanisms. Globally, the induction of TRP metabolism in the majority of cancers is associated with pro-tumoral immunosuppressive microenvironment as well as tumor invasion and proliferation. In vitro and in vivo experiments and clinical trials have been conducted using inhibitors of this pathway. The results from all of these studies were not as conclusive as expected and encountered some setbacks. More specific details and discussions are presented in the following sections.

\subsection{Tryptophan Metabolism: The KYN and 5-HT Pathways}

In mammals, TRP is a rare and essential amino acid provided only by dietary intake. In addition to being a component of proteins, TRP is metabolized through the kynurenine $(\mathrm{KYN})$ or the serotonin (5-HT) pathway to lead to the production of physiologically active metabolites, such as kynurenic acid (KYNA) and NAD ${ }^{+}$or serotonin (5-HT) and melatonin [31] (Figure 1). The first and limiting step of the synthesis of 5-HT is catalyzed by the tryptophan hydroxylase (TPH1). The first and limiting step of the KYN pathway is catalyzed by the tryptophan dioxygenase (TDO2) in the liver or the indoleamine dioxygenase (IDO1/2) in immune cells.

Under physiological conditions, the two pathways are unequal in their ability to degrade TRP as approximately $95 \%$ of free TRP is metabolized via the KYN pathway (of which $90 \%$ occurs in the liver) and about 1\% through the 5-HT pathway. The KYN pathway itself comprises two main branches starting from KYN. The first one ends with KYNA (Figure 1). The second branch is favored under physiological conditions and leads to the production of 5-OH-anthralinic acid (5-OH-AA), the quinolinic and picolinic acids (QUIN and PIC), and of NAD ${ }^{+}$, a principal cofactor in cellular reactions related to energy metabolism, which is inspiring therapies in many diseases [32] (Figure 1).

IDO1 has been shown to be implicated in maternal tolerance towards 'allogeneic concepti' [33], in controlling autoimmune diseases [34,35] and chronic infection [36], as well as promoting tumor immune escape [37-39]. IDO1 was widely reported to be involved in immunosuppression of $\mathrm{T}$ lymphocytes. These actions were attributed to IDO1-caused depletions of TRP as well as to specific effects of TRP metabolites.

$\mathrm{NAD}^{+}$, the end-product of the KYN pathway, has a protective role in cancer, as shown in mice. Impaired TRP metabolism resulting in inhibition of de novo $\mathrm{NAD}^{+}$synthesis in the liver promoted hepatic tumorigenesis through DNA damage [40]. In human gliomas, $\mathrm{NAD}^{+}$produced de novo from TRP confers resistance to the oxidative stress induced by radio-chemotherapy, however, glioma cells and microglia cooperate to produce $\mathrm{NAD}^{+}$[41]. Furthermore, in human cancer cells, IDO1 has been implicated in improving DNA repair and mediating resistance to treatments, such as the PARP inhibitor olaparib, $\gamma$-radiation, and the chemotherapeutic agent cisplatin, by production of $\mathrm{NAD}^{+}$[42]. 


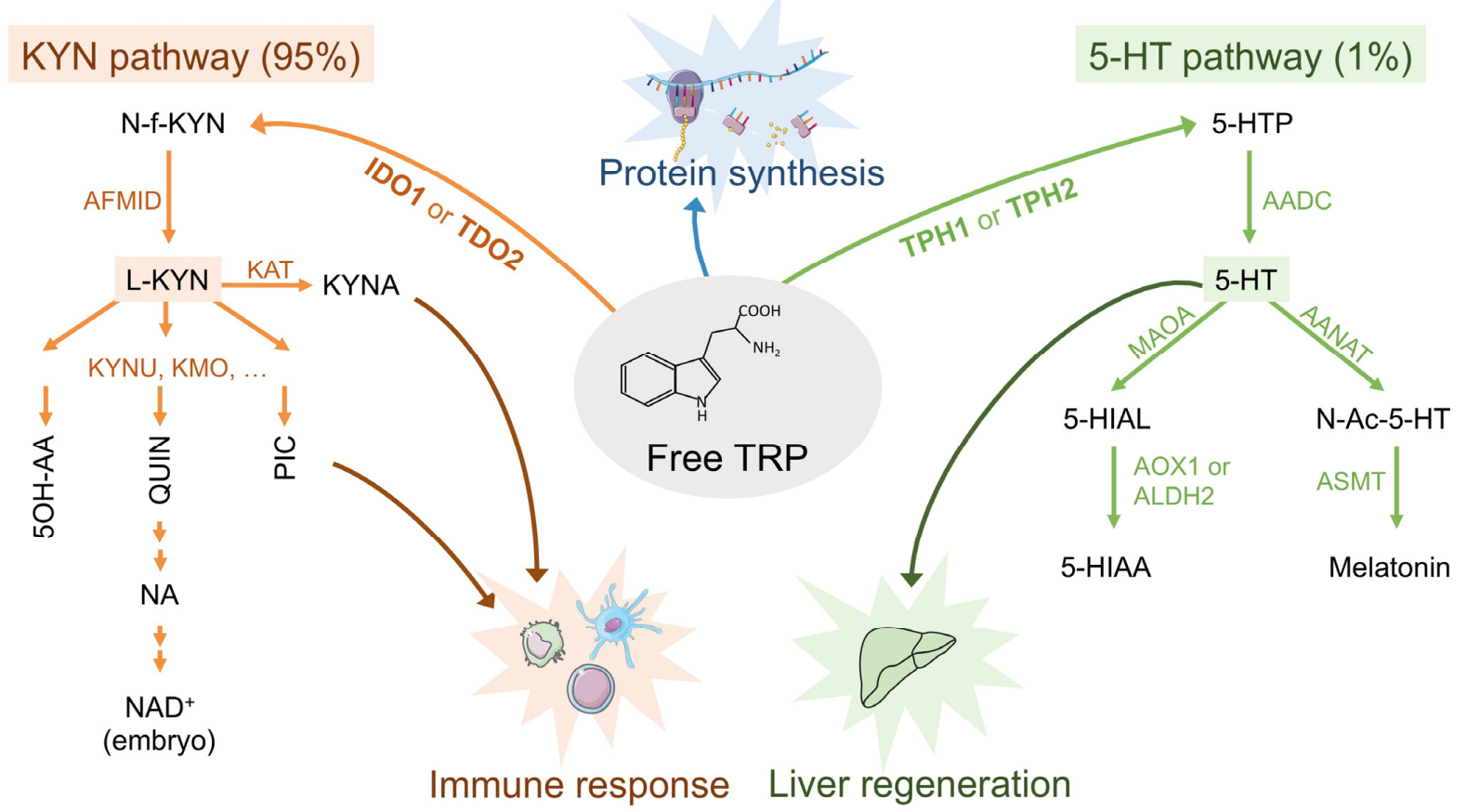

Figure 1. Free tryptophan cellular fate. The first and limiting step of the KYN pathway is catalyzed by tryptophan dioxygenase (TDO2) in the liver or indoleamine dioxygenase (IDO1/2) in immune cells. The first and limiting step of the 5-HT pathway is catalyzed by the tryptophan hydroxylase (TPH1). KYN pathway enzymes: IDO1/2, Indoleamine 2,3-dioxygenase 1/2; TDO2, tryptophan 2,3-dioxygenase; AFMID, arylformamidase; KYNU, kynureninase; KMO, kynurenine 3-monooxygenase; KAT, Kynurenine aminotransferase. KYN pathway metabolites: KYN, kynurenine; N-f-KYN, N-formylkynurenine; KYNA, Kynurenic acid; 5-OH-AA, 5OH-anthralinic acid; QUIN, quinolinic acid; PIC, picolinic acid; NA, nicotinic acid. 5-HT pathway enzymes: TPH1/2, Tryptophan 5-hydroxylase 1/2; AADC, Aromatic-L-amino-acid decarboxylase; MAOA, monoamine oxidase A; AANAT, aralkylamine $\mathrm{N}$-acetyltransferase; AOX1, aldehyde oxidase 1; ALDH2, aldehyde dehydrogenase 2; ASMT, acetylserotonin O-methyltransferase. 5-HT pathway metabolites: 5-HTP 5hydroxytryptophan; 5-HT, serotonin; 5-HIAL, 5-hydroxyindole acetaldehyde; 5-HIAA, 5-hydroxyindole acetate; N-Ac-5-HT, $\mathrm{N}$-acetyl serotonin.

5-HT is not only an hormone and a neurotransmitter, but it also plays a key role in the digestion process and acts as a mitogen for different cell types, including hepatocytes, notably during liver regeneration following injury [43]. Melatonin, the end-product of the 5-HT pathway, controls circadian rhythmicity and could be the link between KYN and 5-HT pathways. Indeed it was shown that melatonin treatment of PC12 cells decreased the expression of AANAT, the first 5-HT transforming enzyme through melatonin production, while it induced the expression of IDO1 by upregulating the expression of the forkhead box protein O1 (FOX1), which binds to the IDO1 promoter and regulates its expression [44].

Recently, the expression of $T D O 2$, the liver specific isoform, was studied at the protein level in HCC samples and other tumors thanks to new monoclonal antibodies [45]. TDO2 protein was found highly present in all of the HCC cells, confirming previous observations at the mRNA level [46] and thus the implication of TDO2 in liver tumorigenesis [47]. This was specific of HCC cells since TDO2 protein was barely detected in other tumor cells, but only in vascular structures in the tumors.

\subsection{Tryptophan Metabolism: Relation to Inflammation}

Immune cells are important sources and processing sites of KYN metabolites, as they express high levels of several enzymes of the KYN pathway such as IDO, KATs, and GPR35. KYNA is generally considered to be neuroprotective but has also been shown to be an agonist of the aryl hydrocarbon receptor (AhR) [48] and of an orphan G-protein-coupled receptor (GPR35) [49], thus regulating the immune and inflammatory responses. As the transcription factor AhR together with IDO1 and TDO2 are present in tumor cells, it has 
been proposed that KYN could have a dual role in promoting cancer invasion and immune escape $[44,46]$.

Immunoregulatory dendritic cells (DCs) regulate T cell responses through IDO1 expression. It has been shown in 2005 that extreme TRP shortage leads to dysfunction of T-cells and antigen-presenting cells (APCs) through accumulation of uncharged tRNA ${ }^{\mathrm{TRP}}$, which activates the GCN2 (general control non-depressible $2 /$ eIF2 $\alpha$ kinase 4 ), a stressresponse kinase. GCN2-knockout $\mathrm{T}$ cell proliferation does not respond to inhibition by IDO-expressing DC from tumor-draining lymph nodes [50].

IFN $\gamma$ strongly increases IDO1 expression in inflammatory sites to prevent immunopathologies or reactions. Activation of IDO1 in the KYN pathway has been reported to suppress the $\mathrm{T}$ cell immune response by activating or differentiating regulatory $\mathrm{T}$ lymphocytes (Treg), which can inhibit the proliferation of other $\mathrm{T}$ cells and thus prevent anti-tumor responses. The action of IDO1/TDO2 leads to the depletion of intracellular TRP and formation of immunosuppressive metabolites such as KYN, which accumulates in the extracellular space, and kynurenic, xanthurenic and cinnabarinic acids, which are all ligands of the aryl hydrocarbon receptor (AHR). Activation of AHR modulates the immune response by modifying the tolerance of $T$ cells and by regulating dendritic cells [41]. The immunological effects of IDO1 are also manifested in macrophages, which can be classified into two types: M1 which are active and have inflammatory properties contributing to the elimination of liver cancer cells; M2 which are "alternatively" active and have antiinflammatory properties promoting the propagation, proliferation, and invasion of cancer cells. IDO1 is highly expressed in M2 macrophages in the tumor microenvironment in $58 \%$ of hepatocellular carcinoma (HCC) cases [51]. The overactivity of IDO1 in these macrophages leads to a decrease in free TRP, which results in negative regulation of CD8+ T cells and inhibits Th17 differentiation. Metabolites of TRP, such as picolinic and 3-hydroxyanthranilic acids, inhibit $\mathrm{T}$ cell proliferation by unknown mechanisms [52].

At the genetic level, it has been shown that IDO1 expression is under the control of Bin1. Bin1 loss elevates the STAT1- and NF-KB-dependent expression of IDO1 [33], driving the escape of oncogenically transformed cells from $\mathrm{T}$ cell-dependent antitumor immunity [37].

Many of these data and information were effective in setting up the scientific mind around the TRP/KYN pathway as being the culprit of immunosuppression, which has to be silenced in order to trigger the immune killing machinery against cancer.

\subsection{Tryptophan Metabolism: Expression Data in $H B$}

RNAseq analyses [24] show a perturbation of TRP metabolism in tumor tissue compared to non-tumor tissue manifested by (i) an increase in the expression of TRP transporters genes (notably SLC1A5), (ii) an overall reduction in the expression of enzymes of the KYN pathway (Figure 2A), notably in the TDO2 gene of the limiting step enzyme, which is the liver-specific isoform, (iii) a non-significant increase in the expression of gene of the TRP to 5-HT conversion enzyme (s) but a significant decrease in the levels of the genes of the other enzymes of this pathway (Figure 2B) and, finally, (iv) a significant increase in three 5-HT receptor genes (5HT1D, 5HT2B, and 5HT4) (Figure 3). 


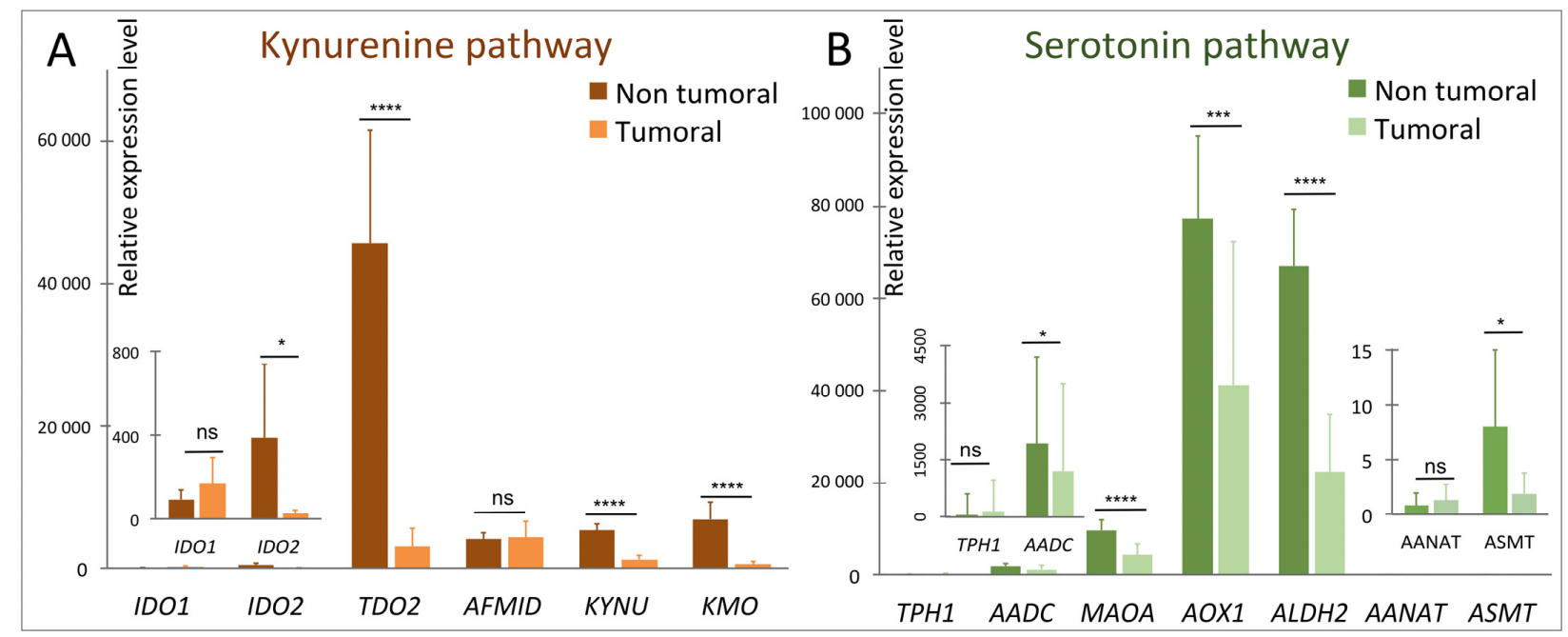

Figure 2. Variation of expression of some of the genes of the kynurenine (A) and serotonin (B) pathways in HB. See legend to Figure 1 for the abbreviations. AANAT and ASMT, coding both for melatonin-synthesizing enzymes, are barely detectable in both non-tumor and tumor samples while TPH1 expression is increased in tumor samples. In HB, the 5-HT pathway would be reduced to 5-HTP production readdressing the question of the balance between KYN and 5-HT pathways in these tumors. (ns, not significant; ${ }^{*}, 1 \times 10^{-2}<p<5 \times 10^{-2} ; * * *, 1 \times 10^{-4}<p<1 \times 10^{-3}$; ${ }^{* * *} p<1 \times 10^{-4}$ ).

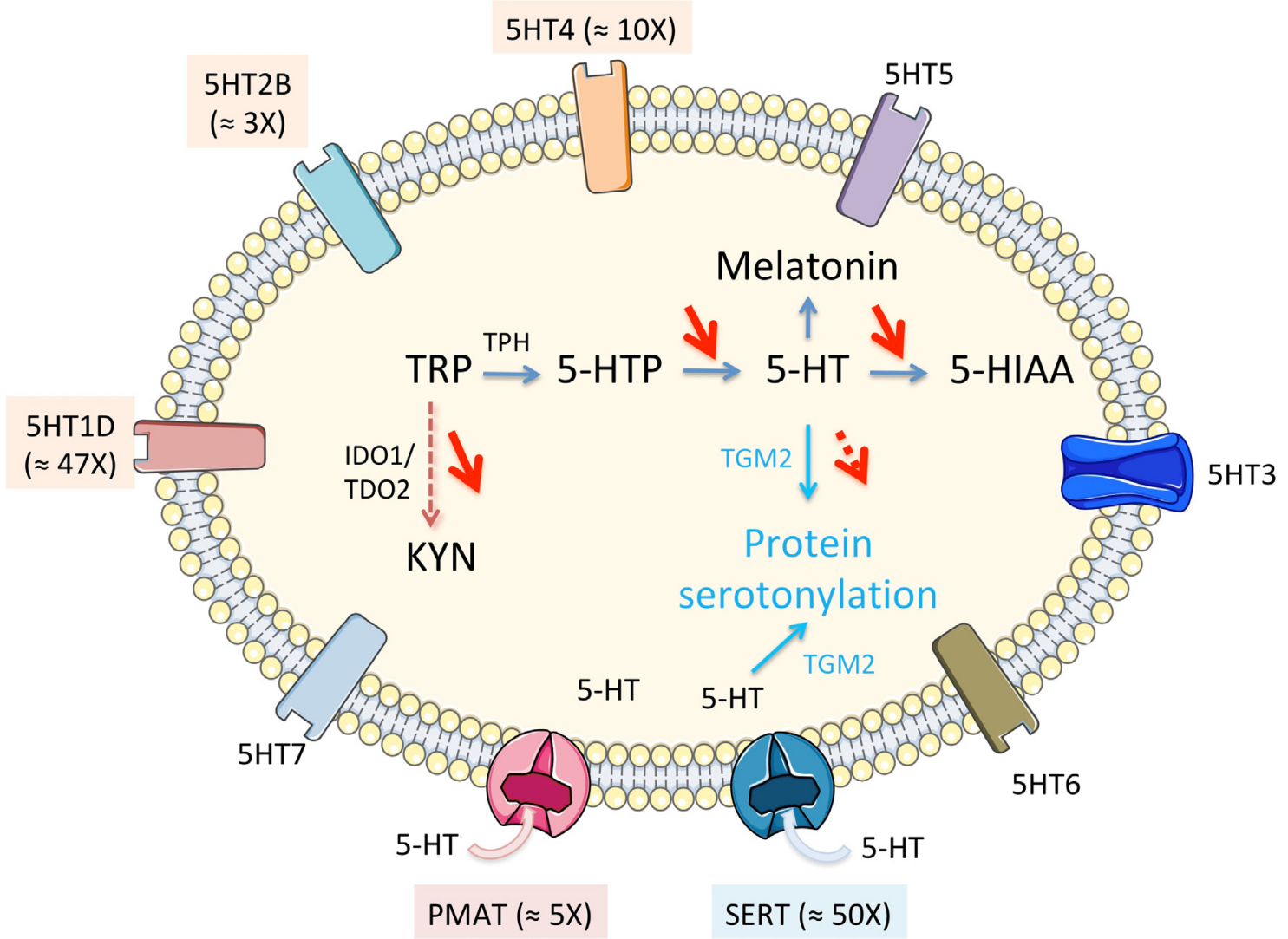

Figure 3. Schematic variations of the seven families of 5-HT receptors (5HT1 to 7), which are a group of G protein coupled receptors (all but 5-HT3) and ligand gated ion channel (5-HT3), and transporters (SERT and PMAT) in the cell membrane. SERT (SLC64A) is specific for serotonin while PMAT (SLC29A4) is a polyspecific organic cation transporter, notably for organic monoamines. PMAT is capable of transporting 5-HT through the plasma membrane, but at a much-reduced capacity as compared to that of SERT. In parentheses, $\approx \mathrm{xX}$ indicates the extent of overexpression in $\mathrm{HB}$ compared to non-tumoral liver. 
The function of TDO2 in the normal liver is to downregulate systemic tryptophan. In $\mathrm{HCC}$, its role would be the protection against immune-mediated tumor rejection. On the contrary, the metabolic context associated with HB could globally reflect an increased need for tryptophan by HB tumor cells, as we have observed that the catabolism of this amino acid in the KYN pathway seems largely reduced (Figure 2A). In addition, its conversion to 5-hydroxy-L-tryptophan (5-HTP) could be increased in parallel with a significant increase in some serotonin receptors and transporters at the tumor level (Figure 3).

SERT is the main 5-HT transporter in mammalian cells and the more specific but other transporters can carry 5-HT through the plasma membrane such as PMAT (Figure 3). The expression of SERT in the cell membrane is regulated by an intricate feedback mechanism involving 5-HT and, in some cases, the membrane-bound 5HT2B receptor. Circulating 5-HT acts to downregulate the expression of SERT on the plasma membrane, meaning that increased plasma concentration of 5-HT leads to a lower rate of uptake by cells [53].

5-HT signaling occurs through a family of membrane-bound receptors specific to 5-HT and named 5HT1 to 5HT7, with several subtypes (Figure 3). The 5HT2 family and the 5HT4 receptor are found primarily in peripheral tissues such as vascular smooth muscle and gastrointestinal tract (GIT) cells and their actions range from smooth muscle contraction in vasoconstriction and gastrointestinal motility to contraction of cardiac tissue causing tachycardia [54]. In healthy liver tissue, 5-HT receptor expression is low. There is evidence that the 5HT2B subtype is present in hepatocytes and is involved in hepatic cell proliferation. Its activation leads to a decrease in glucose uptake by the cells and an increase in lipolysis [55]. Its expression is increased around three times in HB [24]. The other overexpressed receptors are 5HT1D $(\times 47)$ and $5 H T 4(\times 10)$ (Figure 3$)$. Although relatively understudied in its relationship to cancer, the 5-HT1D receptor has been shown to activate the $\beta$-catenin pathway in colorectal cancer and influences metastasis [56]. In healthy tissue it is mainly found in the CNS and its action involves inhibiting neurotransmitter release, so the apparent upregulation in HB is interesting. As the $\beta$-catenin pathway is involved in $80 \%$ of HB it deserves to be further explored in the context of tryptophan metabolism.

To summarize, the unexpected change in the TRP metabolic pathway in the context of HB has the merit of making us reconsider in a more critical way the involvement of this pathway in oncogenesis and immunosuppression.

\subsection{Tryptophan Metabolism: Other Less Known Downtream Metabolites}

From a general viewpoint, the intermediates of amino acid metabolism have been shown to intersect with cellular signaling and this is reviewed in Wang et al. [57]. Activation of RAS/MAPK signaling has been frequently observed in various types of cancer, in line with its key role in promoting cell proliferation and survival. Interestingly, it is effectively suppressed by 5-hydroxyindoleaceticacid (5-HIAA), a product in tryptophan degradation, which could interact with membrane-bound receptors [58]. This metabolite is produced from 5-HT by MAOA and AOX1 in the cytosol or ALDH2 in the mitochondria (Figure 1). Interestingly, these enzymes are downregulated in $\mathrm{HB}$, potentially preserving at least in part the RAS/MAPK signaling and thus tumor growth. 5-HIAA metabolism could potentially be targeted to totally suppress MAPK signaling by providing 5-HIAA precursor, for example.

The 5-HT pathway in HB could induce 5-hydroxytryptophan (HTP) over production. 5-HTP therapeutic effects include treatment of depression, chronic headache, and insomnia. This is another metabolite whose fate in HB could be investigated.

\subsection{Tryptophan Metabolism: Also Involved in Protein Modification}

A post-translational protein modification mechanism involving serotonin, called serotonylation, was discovered more than 60 years ago and has been since implicated in many diverse crucial intracellular processes. Serotonylation is a transamidation leading to the attachment of 5-HT to a protein glutaminyl residue catalyzed by transglutaminase 2 (TGM2) and the blood coagulation factor XIIIa (Figure 4). It results in a modification 
of the function of the recipient protein $[59,60]$. An updated list of serotonylated proteins includes fibronectin, fibrinogen, Rab-3a, Rab-4, Rab-27a, RhoA, Rac, Ras, histones, actins, myosins, Akt, and SERCA2 in various normal or cancerous cells [61]. However, so far nothing is known about the status of protein serotonylation in the liver.



Figure 4. The serotonylation of proteins by TGM2.

TGM2 is expressed all over the body, mainly within the cell, and its function depends on $\mathrm{Ca}^{2+}$ and goes well beyond serotonylation. A specific serotonylation motif has still not been defined. TGM2 is highly expressed in the non-tumor tissue of HB patients and its expression is decreased 3-7 times in the tumor tissues of the same patients [24]. Knowing that serotonylation modifies protein activity and recycling in the cell, TGM2 decrease in HB could have some implications in the regulation of the tumor cell metabolism. The target (s) of this post-translational modification needs to be identified to get a better understanding of the role of the intracellular levels of serotonin in tumor development.

\subsection{Tryptophan Metabolism in Pediatric Liver Cancer: Not the Same as in Adult Liver Cancers}

Considering the metabolo-pathological variations of $\mathrm{HB}$ relative to HCC, the idea of inhibiting the TRP/KYN pathway in order to improve immunotherapy responses does not seem relevant and even counterproductive in an HB-related pathological context. Not surprisingly, there have been failures in clinical trials with IDO inhibitors such as epacadostat. Some researchers and investigators are pushing harder and suggest the use of a combination of TDO2/IDO or COX-2/IDO1 inhibitors [62]. We will therefore see further clinical disappointment if the metabolic crossroads around TRP are not well clarified. 


\section{Therapeutic Targets within the TRP Pathways}

\subsection{Ongoing Clinical Trials}

Given the close relationship between KYN metabolites and inflammatory responses, several drugs targeting COX-2, IDO1, IDO2, or TDO2 are already being tested in clinical trials for the treatment of some cancers ([63] and Table 1), some of which have already been completed. The results of the most advanced clinical trial (Phase 3) using an IDO1 activity inhibitor, epacadostat (trial ECHO-301) have been disappointing for the treatment of metastatic melanoma [62]. Indeed, the combination of epacadostat with pembrolizumab (a reference anti-PD1 treatment in immunotherapy) does not show any beneficial effect of this inhibitor and does not appear to act on the immunosuppressive microenvironment. This failure calls into question the involvement of IDO1 in immunosuppression as well as the usefulness of the IDO1 inhibition strategy. IDO1 is involved in TRP degradation but also in cell signaling and the latter should be targeted along with the catalytic activity [62]. Some researchers have suggested that the immuno-modulatory effect of the inhibitors in preclinical studies may be the consequence of an off-target and independent action of IDO1 inhibition [64]. However, using the IDO inhibitor 1-methyl-tryptophan (1-MT) in association with diverse chemotherapeutic agents, such as cisplatin, cyclophosphamide, and doxorubicin, could effectively promote the regression of breast tumors known to be refractory to chemotherapy [37].

\subsection{Other IDO Inhibitors}

Other drugs targeting the key enzyme of the kynurenine pathway IDO1 have been used in vitro and/or in vivo and are listed in Table 2. 1-MT exists as two stereoisomers, 1-D-MT and 1-L-MT and IDO1 is the preferential target of 1-L-MT, while 1-D-MT, which has been used in clinical trials, preferentially inhibits IDO2 $[65,66]$. Despite the bulk of evidence supporting a role for IDO1 in promoting tumor formation and tumor immune escape, there have been clinical studies showing an anti-tumor effect of IDO1 by the intermediate of IFN- $\gamma$, which was effective in the therapy of ovarian carcinoma and bladder cancer [67-69]. At the preclinical level, a study on pre-immunized mice with tumor antigen has shown that the tumor volume was reduced with 1-methyl-tryptophan (1-MT) and a regression of established breast cancer was observed when 1-MT was combined with chemotherapy [39]. However, other studies have shown that IDO1 expression in tumors positively correlated with progression-free survival and long-term survival $[69,70]$. 
Table 1. List of clinical trials with anti-cancer drugs targeting COX-2, IDO1, or TDO2 in various cancers. Taken from https:/ /clinicaltrials.gov/, last accessed 31 August 2021.

\begin{tabular}{|c|c|c|c|c|c|c|}
\hline Target & Inhibitor & Strategy (Combination) & NCT Number & Phase & Type of Cancer & Status \\
\hline IDO1 & 1-methyl-D-tryptophan & alone & NCT00739609 & 1 & $\begin{array}{l}\text { breast cancer, lung cancer, melanoma, } \\
\text { pancreatic cancer, solid tumors }\end{array}$ & terminated \\
\hline IDO1 & GDC-0919 (navoximod) & alone & NCT02048709 & 1 & solid tumors & completed \\
\hline FIXEDIDO1 & LY3381916 & LY3300054 (anti-PD-L1 checkpoint antibody) & NCT03343613 & 1 & $\begin{array}{l}\text { non-small cell lung cancer, renal cell } \\
\text { carcinoma, triple negative breast cancer }\end{array}$ & terminated \\
\hline IDO1 & NLG802 & alone & NCT03164603 & & advanced solid tumors & completed \\
\hline IDO1 & BMS-986205 & nivolumab + ipilimumab & NCT03459222 & 2 & advanced cancer & recruiting \\
\hline IDO1 & BMS-986205 & alone & NCT03695250 & 1 & liver cancer & active, not recruiting \\
\hline IDO1 & BMS-986205 & nivolumab + temozolomide + radiotherapy & NCT04047706 & 1 & glioblastoma & recruiting \\
\hline IDO1 & epacadostat (INCB024360) & $\begin{array}{l}\text { itacitinib (JAK inhibitor) + INCB050465 PI3K-delta } \\
\text { inhibitor }\end{array}$ & NCT02559492 & 1 & solid tumors & terminated \\
\hline IDO1 & epacadostat (INCB024360) & $\begin{array}{c}\text { nivolumab + anti-GITR monoclonal antibody MK-4166 } \\
+ \text { ipilimumab }\end{array}$ & NCT03707457 & 1 & glioblastoma & terminated \\
\hline \multirow{2}{*}{ IDO1 } & \multirow{2}{*}{ epacadostat (INCB024360) } & ALVAC(2)-NY-ESO-1 (M)/TRICOM vaccine & \multirow{2}{*}{ NCT01982487 } & 1 & \multirow{2}{*}{$\begin{array}{l}\text { epithelial ovarian, fallopian tube, } \\
\text { peritoneal cancer }\end{array}$} & \multirow{2}{*}{ withdrawn } \\
\hline & & alone & & 2 & & \\
\hline IDO1 & epacadostat (INCB024360) & $\begin{array}{l}\text { DEC-205/NY-ESO-1 fusion protein CDX-1401 + Poly } \\
\text { ICLC }\end{array}$ & NCT02166905 & 2 & $\begin{array}{l}\text { fallopian tube carcinoma, ovarian } \\
\text { carcinoma, primary peritoneal carcinoma }\end{array}$ & completed \\
\hline IDO1 & epacadostat (INCB024360) & pembrolizumab & NCT03432676 & 2 & advanced pancreatic cancer & withdrawn \\
\hline IDO1 & epacadostat (INCB024360) & cyclophosphamide & NCT02785250 & 2 & ovarian cancer & active, not recruiting \\
\hline IDO1 & epacadostat (INCB024360) & ipilimumab & NCT01604889 & 2 & metastatic melanoma & terminated \\
\hline \multirow{3}{*}{ IDO1 } & \multirow{3}{*}{ epacadostat (INCB024360) } & $\begin{array}{c}\text { azacitidine (DNA methyltransferase inhibitor) + } \\
\text { pembrolizumab }\end{array}$ & \multirow{3}{*}{ NCT02959437 } & \multirow{3}{*}{2} & \multirow{3}{*}{ metastatic cancer } & \multirow{3}{*}{ terminated } \\
\hline & & INCB057643 + pembrolizumab & & & & \\
\hline & & INCB059872 + pembrolizumab & & & & \\
\hline IDO1 & epacadostat (INCB024360) & $\begin{array}{c}\text { pembrolizumab }+ \text { cisplatin }+ \text { cetuximab + carboplatin } \\
+5 \text {-fluorouracil }\end{array}$ & NCT03358472 & 3 & head and neck cancer & active, not recruiting \\
\hline IDO1 & epacadostat (INCB024360) & pembrolizumab + sunitinib + pazopanib & NCT0360894 & 3 & renal cell carcinoma & active, not recruiting \\
\hline IDO1 and TDO2 & DN1406131 & alone & NCT03641794 & 1 & advanced solid tumors & recruiting \\
\hline IDO1 and TDO2 & HTI-1090 & alone & NCT03208959 & 1 & advanced solid tumors & completed \\
\hline TDO2 and IDO1 & DN1406131 & alone & NCT03641794 & 1 & advanced solid tumors & unknown \\
\hline COX2 & celecoxib $200 \mathrm{mg}$ capsule & alone & NCT03896113 & 2 & endometrial carcinoma & recruiting \\
\hline
\end{tabular}


Table 2. List of molecules or drugs tested as inhibitors of IDO1 and/or TDO2 in vitro, some of which are from the library of the National Institute of Cancer.

\begin{tabular}{|c|c|c|c|c|}
\hline Target & Drug & Development Stage & Observations & Characteristics \\
\hline $\begin{array}{l}\text { IDO1, P38/MAPK pathway, } \\
\text { JNK pathway }\end{array}$ & $\begin{array}{l}\text { 1-L-MT (1-methyl-L-tryptophan) } \\
{[63,64,71]}\end{array}$ & in vitro, in vivo & $\begin{array}{l}\text { delays tumor outgrowth } \\
\text { when combined with } \\
\text { chemotherapeutic agents }\end{array}$ & bioavailable \\
\hline IDO1 inhibitor & $\begin{array}{c}\text { MTH-TRP } \\
\text { (methyl-thiohydantoin-trypt-ophan) } \\
{[37]}\end{array}$ & in vitro, in vivo & $\begin{array}{l}\text { delays tumor outgrowth } \\
\text { when combined with } \\
\text { chemotherapeutic agents }\end{array}$ & $\begin{array}{l}\text { 20-fold more potent than } \\
\text { 1-MT, more rapidly cleared } \\
\text { from serum, bioavailable }\end{array}$ \\
\hline TDO2 inhibitor (mRNA level) & $680 C 91[72]$ & in vitro & & $\begin{array}{c}\text { poor bioavailability, poor } \\
\text { solubility }\end{array}$ \\
\hline TDO2 inhibitor & LM10 [73] & in vitro, in vivo & & $\begin{array}{l}\text { high bioavailability, high } \\
\text { solubility }\end{array}$ \\
\hline IDO1 and TDO2 inhibitor & NSC 26326 or $\beta$-lapachone [74] & in vitro & $\begin{array}{l}\text { more potent inhibitor of } \\
\text { TDO2 than IDO1 }\end{array}$ & $\begin{array}{l}\text { natural quinone isolated from } \\
\text { lapacho tree; topoisomerase I } \\
\text { inhibitor }\end{array}$ \\
\hline $\begin{array}{c}\text { IDO1/TDO2 inhibitor } \\
\text { inhibits DNA synthesis JNK } \\
\text { pathway inducing } \\
\text { upregulation of death } \\
\text { receptors }\end{array}$ & mitomycin C [74] & in vitro & $\begin{array}{l}\text { 8-fold more potent inhibitor } \\
\text { of TDO2 than IDO1 }\end{array}$ & $\begin{array}{c}\text { active on } 74 \text { different tumor } \\
\text { cell lines }\end{array}$ \\
\hline TDO2 inhibitor & $\begin{array}{c}\text { NSC } 36398 \text { (dihydroquercetin, } \\
\text { taxifolin) [74] }\end{array}$ & in vitro & $\begin{array}{l}\text { potent inhibitor of TDO2; no } \\
\text { inhibition of IDO1 }\end{array}$ & $\begin{array}{l}\text { natural flavonoid with low } \\
\text { toxicity }\end{array}$ \\
\hline IDO1 and TDO2 inhibitor & NSC 267461 (nanaomycin A) [74] & in vitro & $\begin{array}{l}\text { more potent inhibitor of } \\
\text { TDO2 than IDO1 }\end{array}$ & $\begin{array}{l}\text { naphtoquinone based } \\
\text { antibiotic; active on } 59 \text { cancer } \\
\text { cell lines }\end{array}$ \\
\hline IDO1 and TDO2 inhibitor & NSC 111041 [74] & in vitro & $\begin{array}{l}\text { more potent inhibitor of } \\
\text { TDO2 than IDO1 }\end{array}$ & $\begin{array}{l}\text { active on colon and breast } \\
\text { cancer cell lines }\end{array}$ \\
\hline IDO1 and TDO2 inhibitor & NSC 255109 [74] & in vitro & $\begin{array}{l}\text { strong inhibitor of both IDO1 } \\
\text { and TDO2 }\end{array}$ & $\begin{array}{l}\text { geldanamycin derivative; } \\
\text { active on } 65 \text { different cell lines }\end{array}$ \\
\hline IDO1 and TDO2 inhibitor & NSC 261726 (3-deazaguanine) [74] & in vitro & $\begin{array}{c}\text { stronger inhibitor of TDO2 } \\
\text { than IDO1 }\end{array}$ & $\begin{array}{c}\text { active on leukemia tumor cell } \\
\text { lines }\end{array}$ \\
\hline
\end{tabular}

In term of mechanism, 1-D-MT inhibits p38 MAPK phosphorylation, preventing the increase of IDO1 mRNA and therefore the increase in KYN production. Additionally, it contributes to the inhibition of JNK signaling, which attenuates the expression of IDO1 mRNA and as a consequence the release of KYN [71]. 1-L-MT, the stereoisomer of 1-D-MT was recently reported to suppress the IFN- $\gamma$-induced expression of IDO1 in mouse rectal carcinoma cells [71]. The TRP-catabolizing enzyme IDO2 was not induced by 1-D-MT. This information sheds light on the different regulation of IDO1 and IDO2 at the tran scriptional level. Uncertainty remains about the clinical significance of IDO1 expression in tumors. However, at some point, it is relevant to link the anti-tumor outcome of 1-D-MT to the induction of IDO1 by IFN- $\gamma$.

Methyl-thiohydantoin-tryptophan (MTH-TRP), another IDO inhibitor, has been discovered and is 20-fold more potent than 1-MT. Its sidechain is a mimetic of the amino acid backbone of tryptophan and it is more soluble in water than 1-MT but it is also more rapidly cleared from serum, both compounds being orally bioavailable [37].

In conclusion, IDO1's expression is known to be immunosuppressive and may be involved in tumor immune escape, but it has also been implicated in direct anti-tumor effects. More studies are needed to better understand the role of IDO1 and IDO2, the implication of their inhibition and to determine whether a correlation exists between these enzymes and other important enzymes of the TRP metabolism such as TDO2.

\subsection{Other TDO2 Inhibitors}

Several studies have reported functional TDO2 expression in various human cancers including bladder, melanoma, and hepatocellular carcinoma [74]. In a preclinical mouse model, it has been shown that TDO2 expression by tumor cells prevented their rejection by immunized animals [75]. Interestingly, this type of immunosuppression prevents 
allograft rejection usually observed after liver transplantation [75]. TDO2 promotes tumor progression through the production of kynurenine, which is an endogenous ligand of the aryl hydrocarbon receptor (AHR), known to be involved in increased tumor cell survival and motility, and reduced anti-tumor immune responses. Altogether, these data suggest that pharmacological inhibition of TDO2 could reactivate the immune system and promote tumor destruction. So far, several compounds were reported as TDO2 inhibitors such as 680C91 [72], which has poor bioavailability and poor solubility, replaced by LM10, which has high bioavailability and solubility [73].

In another study, $\sim 2800$ compounds from the Library of National Cancer Institute USA were screened, among which seven were potent inhibitors of TDO2, with inhibition rates in the nanomolar or low micromolar ranges, and six of them inhibited both IDO1 and TDO2. All these inhibitors have antitumor characteristics on different cancer cell lines [74] (Table 2). NSC 26326 or $\beta$-lapachone, which is a topoisomerase I inhibitor, was the strongest IDO1/TDO2 inhibitor, with $\mathrm{Ki}=97 \pm 14 \mathrm{nM}$ for TDO2 and 30-70 nM for IDO1 [74].

This pharmacological approach may be further extended to a wider range of eligible tumors before entering into clinical studies.

In conclusion, according to some preclinical data pharmacological inhibition of TDO2 and IDO1 might represent a safe and efficient approach to treat cancer by promoting tumoral destruction by the immune system, and consequently potentiating cancer immunotherapies whether it is a single shot inhibition or a two-shot inhibition (IDO1 and TDO2).

\section{Conclusions}

The expression of IDO1 in the majority of cancers is related to immunosuppression, which promotes tumorigenesis, while the expression of $T D O 2$ is responsible for tumor invasion and proliferation. In hepatoblastoma, the role of these two key enzymes of the kynurenine pathway is unknown, as their expression is largely diminished, unlike in other cancers.

In vitro, in vivo, and clinical trials have been undertaken to develop inhibitors of these genes or of others related to the functioning of IDO1 and TDO2. Some of them have been successful, others were not, like the famous combination of epacadostat with an immune checkpoint inhibitor, anti-PD-1/PD-L.

Clinical trials have been completed for inhibitors alone or combined with chemotherapy or monoclonal antibodies. Further studies are needed to more comprehensively evaluate the TRP metabolic node, taking into account the role of the kynurenine pathway and specifically the role of key enzymes in this pathway, in pediatric liver cancer oncogenesis. Will the absence of these enzymes in hepatoblastoma be the cause of immunosuppression and / or the driver of other protumoral activities, unlike what happens in other types of cancer? Further in-depth investigations are required.

Author Contributions: Conceptualization, V.T. and A.J.M.; original draft preparation, V.T. and A.J.M.; writing-review and editing, V.T., H.F. and A.J.M. All authors have read and agreed to the published version of the manuscript.

Funding: This research was funded by the French National Institute of Health and Medical Research (INSERM), the University of Bordeaux, the associations Cassandra contre les Leucémies et Cancers Pédiatriques (OPE-2018-0144) and les Récoltes de l'Espoir (RE-2021-1AD-F), the Cancéropôle, Grand Sud-Ouest (2020-E06), and the Centre National de la Recherche Scientifique (CNRS).

Institutional Review Board Statement: Not applicable.

Informed Consent Statement: Not applicable.

Data Availability Statement: Data from Figure 2 are from Hooks et al. (2018) [24]. Data from Table 1 were taken from https: / / clinicaltrials.gov/, (last accessed 31 August 2021). 
Acknowledgments: The figures were generated with images from SMART-Servier medical art (https://smart.servier.com/, downloaded on 31 January 2021).

Conflicts of Interest: The authors declare no conflict of interest.

\section{References}

1. Ringelhan, M.; Pfister, D.; O'Connor, T.; Pikarsky, E.; Heikenwalder, M. The Immunology of Hepatocellular Carcinoma. Nat. Immunol. 2018, 19, 222-232. [CrossRef] [PubMed]

2. Ferlay, J.; Ervik, M.; Lam, F.; Colombet, M.; Mery, L.; Piñeros, M.; Znaor, A.; Soerjomataram, I.; Bray, F. Global Cancer Observatory: Cancer Today; International Agency for Research on Cancer: Lyon, France, 2018; Available online: http://gco.iarc.fr/today/home (accessed on 4 August 2021).

3. Ferlay, J.; Laversanne, M.; Ervik, M.; Lam, F.; Colombet, M.; Mery, L.; Piñeros, M.; Znaor, A.; Soerjomataram, I.; Bray, F. Global Cancer Observatory: Cancer Tomorrow; International Agency for Research on Cancer: Lyon, France, 2018; Available online: https://gco.iarc.fr/tomorrow/en/dataviz/bubbles?sexes=0\&mode=population\&cancers=11 (accessed on 4 August 2021).

4. Sung, H.; Ferlay, J.; Siegel, R.L.; Laversanne, M.; Soerjomataram, I.; Jemal, A.; Bray, F. Global Cancer Statistics 2020: GLOBOCAN Estimates of Incidence and Mortality Worldwide for 36 Cancers in 185 Countries. CA Cancer J. Clin. 2021, 71, 209-249. [CrossRef]

5. $\quad$ Llovet, J.M.; Kelley, R.K.; Villanueva, A.; Singal, A.G.; Pikarsky, E.; Roayaie, S.; Lencioni, R.; Koike, K.; Zucman-Rossi, J.; Finn, R.S. Hepatocellular Carcinoma. Nat. Rev. Dis. Primers 2021, 7, 6. [CrossRef]

6. Plummer, M.; de Martel, C.; Vignat, J.; Ferlay, J.; Bray, F.; Franceschi, S. Global Burden of Cancers Attributable to Infections in 2012: A Synthetic Analysis. Lancet Glob. Health 2016, 4, e609-e616. [CrossRef]

7. El-Serag, H.B. Hepatocellular Carcinoma. N. Engl. J. Med. 2011, 365, 1118-1127. [CrossRef] [PubMed]

8. Llovet, J.M.; Peña, C.E.A.; Lathia, C.D.; Shan, M.; Meinhardt, G.; Bruix, J.; SHARP Investigators Study Group. Plasma Biomarkers as Predictors of Outcome in Patients with Advanced Hepatocellular Carcinoma. Clin. Cancer Res. 2012, 18, 2290-2300. [CrossRef]

9. Thorgeirsson, S.S.; Grisham, J.W. Molecular Pathogenesis of Human Hepatocellular Carcinoma. Nat. Genet. 2002, 31, 339-346. [CrossRef] [PubMed]

10. Faria, S.C.; Szklaruk, J.; Kaseb, A.O.; Hassabo, H.M.; Elsayes, K.M. TNM/Okuda/Barcelona/UNOS/CLIP International Multidisciplinary Classification of Hepatocellular Carcinoma: Concepts, Perspectives, and Radiologic Implications. Abdom Imaging 2014, 39, 1070-1087. [CrossRef] [PubMed]

11. Llovet, J.M.; Ricci, S.; Mazzaferro, V.; Hilgard, P.; Gane, E.; Blanc, J.-F.; de Oliveira, A.C.; Santoro, A.; Raoul, J.-L.; Forner, A.; et al. Sorafenib in Advanced Hepatocellular Carcinoma. N. Engl. J. Med. 2008, 359, 378-390. [CrossRef]

12. Bruix, J.; Qin, S.; Merle, P.; Granito, A.; Huang, Y.-H.; Bodoky, G.; Pracht, M.; Yokosuka, O.; Rosmorduc, O.; Breder, V.; et al. Regorafenib for Patients with Hepatocellular Carcinoma Who Progressed on Sorafenib Treatment (RESORCE): A Randomised, Double-Blind, Placebo-Controlled, Phase 3 Trial. Lancet 2017, 389, 56-66. [CrossRef]

13. Alipour Talesh, G.; Trézéguet, V.; Merched, A. Hepatocellular Carcinoma and Statins. Biochemistry 2020, 59, 3393-3400. [CrossRef]

14. Raees, A.; Kamran, M.; Özkan, H.; Jafri, W. Updates on the Diagnosis and Management of Hepatocellular Carcinoma. Euroasian J. Hepatogastroenterol. 2021, 11, 32-40. [CrossRef] [PubMed]

15. Alannan, M.; Fayyad-Kazan, H.; Trézéguet, V.; Merched, A. Targeting Lipid Metabolism in Liver Cancer. Biochemistry 2020, 59, 3951-3964. [CrossRef] [PubMed]

16. Darbari, A.; Sabin, K.M.; Shapiro, C.N.; Schwarz, K.B. Epidemiology of Primary Hepatic Malignancies in U.S. Children. Hepatology 2003, 38, 560-566. [CrossRef] [PubMed]

17. Meyers, R.L.; Maibach, R.; Hiyama, E.; Häberle, B.; Krailo, M.; Rangaswami, A.; Aronson, D.C.; Malogolowkin, M.H.; Perilongo, G.; von Schweinitz, D.; et al. Risk-Stratified Staging in Paediatric Hepatoblastoma: A Unified Analysis from the Children's Hepatic Tumors International Collaboration. Lancet Oncol. 2017, 18, 122-131. [CrossRef]

18. Calvisi, D.F.; Solinas, A. Hepatoblastoma: Current Knowledge and Promises from Preclinical Studies. Available online: https: / / pubmed.ncbi.nlm.nih.gov/32632393/ (accessed on 16 September 2020).

19. Marin, J.J.G.; Cives-Losada, C.; Asensio, M.; Lozano, E.; Briz, O.; Macias, R.I.R. Mechanisms of Anticancer Drug Resistance in Hepatoblastoma. Cancers 2019, 11, 407. [CrossRef]

20. Ng, K.; Mogul, D.B. Pediatric Liver Tumors. Clin. Liver Dis. 2018, 22, 753-772. [CrossRef]

21. Koch, A.; Denkhaus, D.; Albrecht, S.; Leuschner, I.; von Schweinitz, D.; Pietsch, T. Childhood Hepatoblastomas Frequently Carry a Mutated Degradation Targeting Box of the Beta-Catenin Gene. Cancer Res. 1999, 59, $269-273$.

22. Clerbaux, L.-A.; Manco, R.; Leclercq, I. Upstream Regulators of Hepatic Wnt/ $\beta$-Catenin Activity Control Liver Metabolic Zonation, Development, and Regeneration. Hepatology 2016, 64, 1361-1363. [CrossRef]

23. Cairo, S.; Armengol, C.; De Reyniès, A.; Wei, Y.; Thomas, E.; Renard, C.-A.; Goga, A.; Balakrishnan, A.; Semeraro, M.; Gresh, L.; et al. Hepatic Stem-like Phenotype and Interplay of Wnt/Beta-Catenin and Myc Signaling in Aggressive Childhood Liver Cancer. Cancer Cell 2008, 14, 471-484. [CrossRef]

24. Hooks, K.B.; Audoux, J.; Fazli, H.; Lesjean, S.; Ernault, T.; Dugot-Senant, N.; Leste-Lasserre, T.; Hagedorn, M.; Rousseau, B.; Danet, C.; et al. New Insights into Diagnosis and Therapeutic Options for Proliferative Hepatoblastoma. Hepatology 2018, 68, 89-102. [CrossRef]

25. Hanahan, D.; Weinberg, R.A. Hallmarks of Cancer: The Next Generation. Cell 2011, 144, 646-674. [CrossRef] 
26. Goldberg, M.L.; Biava, C.G. The Effects of Glucose and Cyclic GMP on RNA Synthesis and Nuclear Morphology in Starved Rats. Biochim. Biophys. Acta 1976, 454, 457-468. [CrossRef]

27. Lee, S.-W.; Zhang, Y.; Jung, M.; Cruz, N.; Alas, B.; Commisso, C. EGFR-Pak Signaling Selectively Regulates Glutamine DeprivationInduced Macropinocytosis. Dev. Cell 2019, 50, 381-392.e5. [CrossRef] [PubMed]

28. Wang, Y.-P.; Lei, Q.-Y. Metabolite Sensing and Signaling in Cell Metabolism. Signal Transduct. Target. Ther. 2018, 3, 30. [CrossRef]

29. Efeyan, A.; Comb, W.C.; Sabatini, D.M. Nutrient-Sensing Mechanisms and Pathways. Nature 2015, 517, 302-310. [CrossRef]

30. Waitkus, M.S.; Diplas, B.H.; Yan, H. Biological Role and Therapeutic Potential of IDH Mutations in Cancer. Cancer Cell 2018, 34, 186-195. [CrossRef]

31. Guillemin, G.J.; Brew, B.J. Implications of the Kynurenine Pathway and Quinolinic Acid in Alzheimer's Disease. Redox Rep. 2002, 7, 199-206. [CrossRef] [PubMed]

32. Cantó, C.; Menzies, K.J.; Auwerx, J. NAD (+) Metabolism and the Control of Energy Homeostasis: A Balancing Act between Mitochondria and the Nucleus. Cell Metab. 2015, 22, 31-53. [CrossRef]

33. Munn, D.H.; Zhou, M.; Attwood, J.T.; Bondarev, I.; Conway, S.J.; Marshall, B.; Brown, C.; Mellor, A.L. Prevention of Allogeneic Fetal Rejection by Tryptophan Catabolism. Science 1998, 281, 1191-1193. [CrossRef] [PubMed]

34. Opitz, C.A.; Wick, W.; Steinman, L.; Platten, M. Tryptophan Degradation in Autoimmune Diseases. Cell Mol. Life Sci. 2007, 64, 2542-2563. [CrossRef]

35. Platten, M.; Ho, P.P.; Youssef, S.; Fontoura, P.; Garren, H.; Hur, E.M.; Gupta, R.; Lee, L.Y.; Kidd, B.A.; Robinson, W.H.; et al. Treatment of Autoimmune Neuroinflammation with a Synthetic Tryptophan Metabolite. Science 2005, 310, 850-855. [CrossRef] [PubMed]

36. Zelante, T.; Fallarino, F.; Bistoni, F.; Puccetti, P.; Romani, L. Indoleamine 2,3-Dioxygenase in Infection: The Paradox of an Evasive Strategy That Benefits the Host. Microbes Infect. 2009, 11, 133-141. [CrossRef]

37. Muller, A.J.; DuHadaway, J.B.; Donover, P.S.; Sutanto-Ward, E.; Prendergast, G.C. Inhibition of Indoleamine 2,3-Dioxygenase, an Immunoregulatory Target of the Cancer Suppression Gene Bin1, Potentiates Cancer Chemotherapy. Nat. Med. 2005, 11, 312-319. [CrossRef]

38. Munn, D.H.; Mellor, A.L. Indoleamine 2,3-Dioxygenase and Tumor-Induced Tolerance. J. Clin. Investig. 2007, 117, 1147-1154. [CrossRef]

39. Uyttenhove, C.; Pilotte, L.; Théate, I.; Stroobant, V.; Colau, D.; Parmentier, N.; Boon, T.; Van den Eynde, B.J. Evidence for a Tumoral Immune Resistance Mechanism Based on Tryptophan Degradation by Indoleamine 2,3-Dioxygenase. Nat. Med. 2003, 9 , 1269-1274. [CrossRef]

40. Tummala, K.S.; Gomes, A.L.; Yilmaz, M.; Graña, O.; Bakiri, L.; Ruppen, I.; Ximénez-Embún, P.; Sheshappanavar, V.; RodriguezJusto, M.; Pisano, D.G.; et al. Inhibition of de Novo NAD (+) Synthesis by Oncogenic URI Causes Liver Tumorigenesis through DNA Damage. Cancer Cell 2014, 26, 826-839. [CrossRef] [PubMed]

41. Platten, M.; Nollen, E.A.A.; Röhrig, U.F.; Fallarino, F.; Opitz, C.A. Tryptophan Metabolism as a Common Therapeutic Target in Cancer, Neurodegeneration and Beyond. Nat. Rev. Drug Discov. 2019, 18, 379-401. [CrossRef] [PubMed]

42. Zhai, L.; Bell, A.; Ladomersky, E.; Lauing, K.L.; Bollu, L.; Sosman, J.A.; Zhang, B.; Wu, J.D.; Miller, S.D.; Meeks, J.J.; et al. Immunosuppressive IDO in Cancer: Mechanisms of Action, Animal Models, and Targeting Strategies. Front. Immunol. 2020, 11, 1185. [CrossRef] [PubMed]

43. Ruddell, R.G.; Mann, D.A.; Ramm, G.A. The Function of Serotonin within the Liver. J. Hepatol. 2008, 48, 666-675. [CrossRef]

44. Li, Y.; Hu, N.; Yang, D.; Oxenkrug, G.; Yang, Q. Regulating the Balance between the Kynurenine and Serotonin Pathways of Tryptophan Metabolism. FEBS J. 2017, 284, 948-966. [CrossRef] [PubMed]

45. Hoffmann, D.; Dvorakova, T.; Stroobant, V.; Bouzin, C.; Daumerie, A.; Solvay, M.; Klaessens, S.; Letellier, M.-C.; Renauld, J.-C.; van Baren, N.; et al. Tryptophan 2,3-Dioxygenase Expression Identified in Human Hepatocellular Carcinoma Cells and in Intratumoral Pericytes of Most Cancers. Cancer Immunol. Res. 2020, 8, 19-31. [CrossRef]

46. Opitz, C.A.; Litzenburger, U.M.; Sahm, F.; Ott, M.; Tritschler, I.; Trump, S.; Schumacher, T.; Jestaedt, L.; Schrenk, D.; Weller, M.; et al. An Endogenous Tumour-Promoting Ligand of the Human Aryl Hydrocarbon Receptor. Nature 2011, 478, 197-203. [CrossRef] [PubMed]

47. Li, S.; Li, L.; Wu, J.; Song, F.; Qin, Z.; Hou, L.; Xiao, C.; Weng, J.; Qin, X.; Xu, J. TDO Promotes Hepatocellular Carcinoma Progression. Onco Targets Ther. 2020, 13, 5845-5855. [CrossRef]

48. DiNatale, B.C.; Murray, I.A.; Schroeder, J.C.; Flaveny, C.A.; Lahoti, T.S.; Laurenzana, E.M.; Omiecinski, C.J.; Perdew, G.H. Kynurenic Acid Is a Potent Endogenous Aryl Hydrocarbon Receptor Ligand That Synergistically Induces Interleukin-6 in the Presence of Inflammatory Signaling. Toxicol. Sci. 2010, 115, 89-97. [CrossRef] [PubMed]

49. Wang, J.; Simonavicius, N.; Wu, X.; Swaminath, G.; Reagan, J.; Tian, H.; Ling, L. Kynurenic Acid as a Ligand for Orphan G Protein-Coupled Receptor GPR35. J. Biol. Chem. 2006, 281, 22021-22028. [CrossRef]

50. Munn, D.H.; Sharma, M.D.; Baban, B.; Harding, H.P.; Zhang, Y.; Ron, D.; Mellor, A.L. GCN2 Kinase in T Cells Mediates Proliferative Arrest and Anergy Induction in Response to Indoleamine 2,3-Dioxygenase. Immunity 2005, 22, 633-642. [CrossRef]

51. Théate, I.; van Baren, N.; Pilotte, L.; Moulin, P.; Larrieu, P.; Renauld, J.-C.; Hervé, C.; Gutierrez-Roelens, I.; Marbaix, E.; Sempoux, C.; et al. Extensive Profiling of the Expression of the Indoleamine 2,3-Dioxygenase 1 Protein in Normal and Tumoral Human Tissues. Cancer Immunol. Res. 2015, 3, 161-172. [CrossRef] 
52. Mazzone, M.; Menga, A.; Castegna, A. Metabolism and TAM Functions-It Takes Two to Tango. FEBS J. 2018, $285,700-716$. [CrossRef]

53. Jørgensen, T.N.; Christensen, P.M.; Gether, U. Serotonin-Induced down-Regulation of Cell Surface Serotonin Transporter. Neurochem. Int. 2014, 73, 107-112. [CrossRef]

54. Hoyer, D.; Clarke, D.E.; Fozard, J.R.; Hartig, P.R.; Martin, G.R.; Mylecharane, E.J.; Saxena, P.R.; Humphrey, P.P. International Union of Pharmacology Classification of Receptors for 5-Hydroxytryptamine (Serotonin). Pharmacol. Rev. 1994, 46, 157-203.

55. Sumara, G.; Sumara, O.; Kim, J.K.; Karsenty, G. Gut-Derived Serotonin Is a Multifunctional Determinant to Fasting Adaptation. Cell Metab. 2012, 16, 588-600. [CrossRef]

56. Sui, H.; Xu, H.; Ji, Q.; Liu, X.; Zhou, L.; Song, H.; Zhou, X.; Xu, Y.; Chen, Z.; Cai, J.; et al. 5-Hydroxytryptamine Receptor (5-HT1DR) Promotes Colorectal Cancer Metastasis by Regulating Axin1/ $\beta$-Catenin/MMP-7 Signaling Pathway. Oncotarget 2015, 6, 25975-25987. [CrossRef]

57. Wang, Y.-P.; Li, J.-T.; Qu, J.; Yin, M.; Lei, Q.-Y. Metabolite Sensing and Signaling in Cancer. J. Biol. Chem. 2020, 295, 11938-11946. [CrossRef]

58. Schmid, T.; Snoek, L.B.; Fröhli, E.; van der Bent, M.L.; Kammenga, J.; Hajnal, A. Systemic Regulation of RAS/MAPK Signaling by the Serotonin Metabolite 5-HIAA. PLoS Genet. 2015, 11, e1005236. [CrossRef]

59. Walther, D.J.; Peter, J.-U.; Winter, S.; Höltje, M.; Paulmann, N.; Grohmann, M.; Vowinckel, J.; Alamo-Bethencourt, V.; Wilhelm, C.S.; Ahnert-Hilger, G.; et al. Serotonylation of Small GTPases Is a Signal Transduction Pathway That Triggers Platelet Alpha-Granule Release. Cell 2003, 115, 851-862. [CrossRef]

60. Farrelly, L.A.; Thompson, R.E.; Zhao, S.; Lepack, A.E.; Lyu, Y.; Bhanu, N.V.; Zhang, B.; Loh, Y.-H.E.; Ramakrishnan, A.; Vadodaria, K.C.; et al. Histone Serotonylation Is a Permissive Modification That Enhances TFIID Binding to H3K4me3. Nature 2019, 567, 535-539. [CrossRef] [PubMed]

61. Bader, M. Serotonylation: Serotonin Signaling and Epigenetics. Front. Mol. Neurosci. 2019, 12, 288. [CrossRef] [PubMed]

62. Van den Eynde, B.J.; van Baren, N.; Baurain, J.-F. Is There a Clinical Future for IDO1 Inhibitors After the Failure of Epacadostat in Melanoma? Annu. Rev. Cancer Biol. 2020, 4, 241-256. [CrossRef]

63. Opitz, C.A.; Somarribas Patterson, L.F.; Mohapatra, S.R.; Dewi, D.L.; Sadik, A.; Platten, M.; Trump, S. The Therapeutic Potential of Targeting Tryptophan Catabolism in Cancer. Br. J. Cancer 2020, 122, 30-44. [CrossRef] [PubMed]

64. Günther, J.; Däbritz, J.; Wirthgen, E. Limitations and Off-Target Effects of Tryptophan-Related IDO Inhibitors in Cancer Treatment. Front. Immunol. 2019, 10, 1801. [CrossRef] [PubMed]

65. Löb, S.; Königsrainer, A.; Zieker, D.; Brücher, B.L.D.M.; Rammensee, H.-G.; Opelz, G.; Terness, P. IDO1 and IDO2 Are Expressed in Human Tumors: Levo- but Not Dextro-1-Methyl Tryptophan Inhibits Tryptophan Catabolism. Cancer Immunol. Immunother. 2009, 58, 153-157. [CrossRef]

66. Tomchuck, S.L.; Henkle, S.L.; Coffelt, S.B.; Betancourt, A.M. Toll-Like Receptor 3 and Suppressor of Cytokine Signaling Proteins Regulate CXCR4 and CXCR7 Expression in Bone Marrow-Derived Human Multipotent Stromal Cells. PLoS ONE 2012, 7, e39592. [CrossRef]

67. Giannopoulos, A.; Constantinides, C.; Fokaeas, E.; Stravodimos, C.; Giannopoulou, M.; Kyroudi, A.; Gounaris, A. The Immunomodulating Effect of Interferon- $\gamma$ Intravesical Instillations in Preventing Bladder Cancer Recurrence. Clin. Cancer Res. 2003, $9,5550-5558$.

68. Windbichler, G.H.; Hausmaninger, H.; Stummvoll, W.; Graf, A.H.; Kainz, C.; Lahodny, J.; Denison, U.; Müller-Holzner, E.; Marth, C. Interferon-Gamma in the First-Line Therapy of Ovarian Cancer: A Randomized Phase III Trial. Br. J. Cancer 2000, 82, 1138-1144. [CrossRef]

69. Ishio, T.; Goto, S.; Tahara, K.; Tone, S.; Kawano, K.; Kitano, S. Immunoactivative Role of Indoleamine 2,3-Dioxygenase in Human Hepatocellular Carcinoma. J. Gastroenterol. Hepatol. 2004, 19, 319-326. [CrossRef] [PubMed]

70. Riesenberg, R.; Weiler, C.; Spring, O.; Eder, M.; Buchner, A.; Popp, T.; Castro, M.; Kammerer, R.; Takikawa, O.; Hatz, R.A.; et al. Expression of Indoleamine 2,3-Dioxygenase in Tumor Endothelial Cells Correlates with Long-Term Survival of Patients with Renal Cell Carcinoma. Clin. Cancer. Res. 2007, 13, 6993-7002. [CrossRef]

71. Opitz, C.A.; Litzenburger, U.M.; Opitz, U.; Sahm, F.; Ochs, K.; Lutz, C.; Wick, W.; Platten, M. The Indoleamine-2,3-Dioxygenase (IDO) Inhibitor 1-Methyl-D-Tryptophan Upregulates IDO1 in Human Cancer Cells. PLoS ONE 2011, 6, e19823. [CrossRef]

72. Salter, M.; Hazelwood, R.; Pogson, C.I.; Iyer, R.; Madge, D.J. The Effects of a Novel and Selective Inhibitor of Tryptophan 2,3-Dioxygenase on Tryptophan and Serotonin Metabolism in the Rat. Biochem. Pharmacol. 1995, 49, 1435-1442. [CrossRef]

73. Dolusić, E.; Larrieu, P.; Moineaux, L.; Stroobant, V.; Pilotte, L.; Colau, D.; Pochet, L.; Van den Eynde, B.; Masereel, B.; Wouters, J.; et al. Tryptophan 2,3-Dioxygenase (TDO) Inhibitors. 3-(2-(Pyridyl)Ethenyl)Indoles as Potential Anticancer Immunomodulators. J. Med. Chem. 2011, 54, 5320-5334. [CrossRef]

74. Pantouris, G.; Mowat, C.G. Antitumour Agents as Inhibitors of Tryptophan 2,3-Dioxygenase. Biochem. Biophys. Res. Commun. 2014, 443, 28-31. [CrossRef] [PubMed]

75. Pilotte, L.; Larrieu, P.; Stroobant, V.; Colau, D.; Dolušić, E.; Frédérick, R.; Plaen, E.D.; Uyttenhove, C.; Wouters, J.; Masereel, B.; et al. Reversal of Tumoral Immune Resistance by Inhibition of Tryptophan 2,3-Dioxygenase. Proc. Natl. Acad. Sci. USA 2012, 109, 2497-2502. [CrossRef] [PubMed] 